\title{
Funcionalidad turística de la gestión de la comunicación en redes sociales de museos de Málaga
}

\section{Tourist functionality of the communication management on Malaga's museums' social networks}
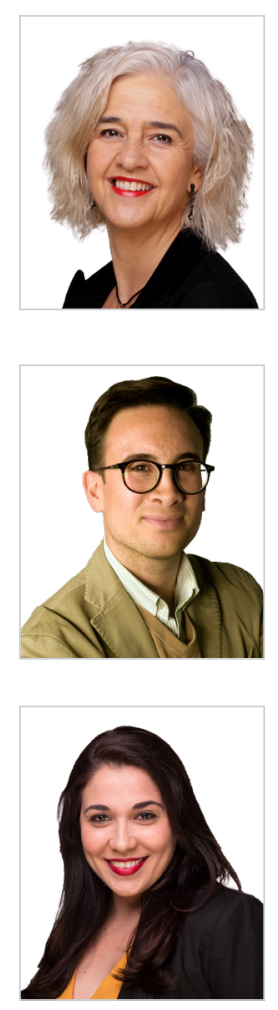

Emelina Galarza Fernández. Profesora asociada de la Facultad de Ciencias de la Comunicación de la Universidad de Málaga e imparte docencia de Máster en otras universidades andaluzas. Licenciada en Derecho y Doctora en Comunicación, especializada en estudios de género y comunicación, así como en comunicación organizacional. Entre sus líneas de investigación destaca la ciber-acción de organizaciones políticas, empresariales o sociales, así como los marcos normativos y la comunicación. Actualmente, dirige su propia empresa, además de presidir una asociación feminista y de mujeres de ámbito nacional.

Universidad de Málaga, España

meligalarza@uma.es

ORCID: 0000-0002-8299-7179

Eduardo Villena Alarcón. Licenciado en periodismo, publicidad y relaciones públicas, Eduardo Villena Alarcón es doctor en Comunicación Organizacional por la Universidad de Málaga, España. Su línea de investigación versa en torno a la dirección y gestión de la comunicación corporativa. Miembro del grupo de investigación "las relaciones públicas en la pequeña y mediana empresa” y socio de la AE-IC y AIRRPP, actualmente imparte docencia en la UMA de las asignaturas Método Científico e Investigación en Comunicación y Creación de Campañas en Entornos Digitales. También ha sido Asociado en la Universidad de Murcia. Universidad de Málaga, España

eduardo.villena@uma.es

ORCID: 0000-0001-8798-8506

Aimiris Sosa Valcarcel. Doctoranda del Programa Interuniversitario en Comunicación de las Universidades de Cádiz, Huelva, Málaga y Sevilla. Docente e investigadora del Departamento de Comunicación Audiovisual y Publicidad de la Universidad de Málaga, por concesión de una beca FPU del Ministerio de Educación, Cultura y Deporte de España. Sus líneas de investigación se centran en el estudio de la comunicación política, el periodismo y los medios digitales en general. Es Máster en Gestión Estratégica e Innovación en Comunicación por la Universidad de Málaga. Licenciada en Periodismo por la Universidad Central "Marta Abreu" de Las Villas, Cuba. Universidad de Málaga, España

aimirissosa@uma.es

ORCID: 0000-0001-8480-8063

Cómo citar este artículo:

Galarza Fernández, E.; Villena Alarcón, E. y Sosa Valcarcel, A. (2020). Funcionalidad turística de la gestión de la comunicación en redes sociales de museos de Málaga. Doxa Comunicación, 30, pp. 309-330.

https://doi.org/10.31921/doxacom.n30a16 
Recibido: 15/01/2020 - Aceptado: 16/04/2020

\section{Resumen:}

Esta investigación centra su objeto de estudio en la gestión comunicativa del patrimonio cultural que realizan en redes sociales el Centro de Arte Contemporáneo, el Museo Picasso y la Casa Natal, el Pompidou y el Carmen Thyssen; instituciones malagueñas que constituyen un reclamo turístico competitivo, y que permiten que la capital de la Costa del Sol se posicione como una ciudad de museos. A partir del análisis de contenido de los perfiles institucionales de estos centros en redes sociales y de la realización de entrevistas semiestructuradas a las responsables de comunicación, se obtiene que estas plataformas han fomentado nuevas formas de consumo del producto cultural que preservan los museos. Al mismo tiempo, la gestión de la comunicación en el espacio digital ha tenido un impacto en la funcionalidad turística de estas instituciones, lo cual se traduce en un aumento del número de visitas que reciben anualmente. Se concluye que el atractivo turístico que generan los museos es resultado tanto de la gestión institucional de la comunicación, como del contenido generado por los propios usuarios de la web, quienes contribuyen a una mayor visibilidad de los museos y a su reconocimiento como actividad de ocio y vacaciones.

\section{Palabras clave:}

Comunicación estratégica; turismo; cultura; museos; redes sociales.
Received: 15/01/2020 - Accepted: 16/04/2020

\section{Abstract:}

This research focuses on the communication management of cultural heritage that the Contemporary Art Centre of Malaga, Picasso Museum, Casa Natal, the Pompidou, and Carmen Thyssen carry out. They are institutions from Malaga that are competitive touristic attractions, allowing the capital of the Costa del Sol to position itself as a city of museums. Based on the content analysis of the institutional profiles of these centres on social networks and from semi-structured interviews with communication managers, these new forms of communication have fostered new ways of consuming the museums' cultural products. Simultaneously, communication management in the digital space has had an impact on the tourist functionality of these institutions, increasing the number of visitors they receive annually. It can be seen that museums are a tourist attraction as a result of both institutional communication management and the content generated by users on their websites, who contribute to great.

\section{Keywords:}

Strategic communication; tourism; culture; museums; social media.

\section{Introducción}

En la última década la gestión estratégica de la comunicación en instituciones culturales ha mostrado resultados satisfactorios (Merín, 2018), sobre todo a partir de la consecución de objetivos y la realización de proyectos y actividades que tienen lugar en el marco de la razón social de estas organizaciones (Lazzeretti, Sartori \& Innocenti, 2015).

La toma de conciencia global sobre la necesidad de democratizar la cultura ha propiciado una mayor implicación de los públicos, tanto de los que intervienen directamente en el funcionamiento de estas instituciones, el personal que las visita, recomienda o valora, como de aquellos colectivos que "pueden apoyar la acción de la entidad, como pueden ser expertos, medios de comunicación o asociaciones" (Oliveira y Capriotti, 2013: 213).

Por lo general, en España los estudios sobre organizaciones culturales han tenido como unidad de análisis a los centros más importantes del mundo, basados fundamentalmente en la dimensión del patrimonio que atesoran o en el volumen de visitas que reciben (Losada y Capriotti, 2015; Mas, 2018; Cano y Rostoll, 2018; Claes y Deltell, 2019; Mateos, 2019). Sin embargo, existen en el país instituciones con menor notoriedad, cuyo valor patrimonial o de identidad cultural le conceden también un alto interés turístico, en tanto fuentes de ocio y conocimiento. Es el caso de algunos museos, a menudo ubicados fuera de la capital nacional o de las regionales, con una oferta que posiciona a las ciudades que los albergan como destino cultural dentro del entramado turístico internacional. 
Esta investigación se interesa por conocer qué beneficios aporta a los museos de Málaga-Centro de Arte Contemporáneo (CAC), el Museo Picasso y la Casa Natal, el Pompidou y el Carmen Thyssen- la gestión comunicativa de su patrimonio cultural en redes sociales. Se persigue describir cómo se estructuran los departamentos de comunicación desde los cuales se gestionan las redes sociales corporativas de estos museos; identificar las redes sociales en las que tienen presencia; determinar el impacto que tiene la gestión comunicativa de los perfiles institucionales de estos museos en redes sociales; así como valorar si dicho impacto se traduce en beneficios concretos para estas organizaciones.

Si bien múltiples investigaciones se han enfocado en el sector museístico para estudiar la comunicación corporativa online y offline de sus instituciones (Viñarás, Cabezuelo y Herranz 2011; Jiménez, 2016; Cordón y González, 2016), sus departamentos de comunicación, perfiles y funciones (Viñarás, 2009; 2011); conocer la forma en que gestionan sus públicos, las motivaciones y opiniones de los visitantes (Oliveira y Capriotti, 2013; Becerra y Domínguez, 2014; Parguiña, 2015; Panozzo, 2018), la eficiencia de las acciones de comunicación que realizan (Santos, 2012), los recursos de los que disponen (Viñarás, 2005; Soler, 2017), o la estrategia comunicativa que desarrollan (Martínez, 2012; Lazzeretti, Sartori \& Innocenti, 2015; Caerols, Viñarás y Gonzálvez, 2017; Chic, 2018); la novedad del estudio que aquí se propone radica en demostrar cómo una gestión comunicativa eficaz de redes sociales corporativas de museos locales puede contribuir a un aumento de la funcionalidad turística de su patrimonio "sin agredir ni su naturaleza, ni su carácter" (Velasco, 2009: 238).

\section{Turismo, cultura y comunicación en redes sociales}

El auge alcanzado por el sector cultural se encuentra estrechamente relacionado con el desarrollo de la industria turística a nivel mundial. Según datos del Ministerio de Industria, Comercio y Turismo (2019: 3), España lidera este sector, que "constituye uno de los principales pilares de nuestra economía, fuente de ingresos (aporta el 11,7\% del PIB), y de generación de empleo, (emplea al 12,2\%) del total de afiliados".

De la gama de servicios turísticos que se ofrecen anualmente en el país, "el producto más relevante ha sido arte y cultura española, 21\% del total" (Instituto de Turismo de España, 2018: 7). Esta cifra queda avalada por el volumen de viajes de ocio, recreo o vacaciones realizados en 2018 por turistas nacionales y extranjeros hacia cualquier destino del país, de los cuales el 14,5\% (viajes de nacionales) y el 17,5\% (viajes de extranjeros) fueron iniciados por motivos culturales (Ministerio de Cultura y Deporte, 2019).

Ello se sustenta en el hecho de que "España es el segundo país del mundo en patrimonio histórico cultural declarado protegido por la UNESCO (Patrimonio de la humanidad)" (Ministerio de Industria, Comercio y Turismo, 2019: 7); y que uno de los principios contemplados en las Directrices Generales de la Estrategia de Turismo Sostenible de España 2030 resulta la "preservación de los valores naturales y culturales, partiendo de la base que la conservación de nuestro extenso patrimonio cultural y natural es un objetivo prioritario" (Ministerio de Industria, Comercio y Turismo, 2019: 10).

De acuerdo con Viñarás, Cabezuelo y Herranz (2011) uno de los mayores atractivos culturales que ofrecen los destinos turísticos son los museos, ya que conservan parte de la riqueza artística de las naciones, expuesta al público de manera permanente o temporal. A pesar del ligero descenso que ha experimentado el volumen de museos existentes en España 
hasta 2018, el Anuario de Estadísticas Culturales estima que estas instituciones recibieron "65,4 millones de visitantes a lo largo de 2018, cifra que supone un incremento del 9,2\% respecto a 2016” (Ministerio de Cultura y Deporte, 2019: 37).

La investigación científica ha demostrado que en los últimos años el aumento del número de visitas a las instituciones culturales y, específicamente a los museos, se deriva en gran medida de las motivaciones de los visitantes (Hood, 1983; Falk, 2012; Menor, 2019) y de sus características psicosociales: "sus valores, actitudes, percepciones, intereses y satisfacciones" (Parguiña, 2015: 18). Así, un estudio de la Subdirección General de Museos Estatales sobre el perfil del visitante reconoce que:

el ideario colectivo sobre los museos, lo que opina el público potencial sobre ellos, cómo los ven, cómo o con quién planean la visita o qué esperan obtener de la misma es una información muy valiosa que permite variar la comunicación y orientarla a ese público potencial que no asiste a los museos porque tiene una serie de ideas que impiden esta decisión (Subdirección General de Museos Estatales, 2012: 7).

Con este fin, desde los departamentos y áreas destinadas a la gestión de la comunicación institucional se realizan acciones para alcanzar y mantener relaciones estables con los públicos (Van Riel, 2005; Gürel \& Kavak, 2010; Viñarás, 2011; Oksuz \& Gorpe, 2019; Salmon, Poorisat \& Kim, 2019), entendidos como "personas u organizaciones que tienen interés e influencia en la capacidad del museo para lograr sus objetivos" (Legget, 2009: 214). Al mismo tiempo, "en este proceso comunicativo, la institución transmite -simbólica y conductualmente- aquellos valores y rasgos que le caracterizan, y que forman la imagen, a través de las percepciones y experiencias, en la mente de cada persona y grupo" (Viñarás, Cabezuelo y Herranz, 2011: 565).

Numerosos autores destacan la importancia del carácter estratégico de la gestión de la comunicación, tanto a nivel interno como externo, ya que permite, a partir de la información obtenida en diagnósticos previos, proyectar posibles escenarios, plantear objetivos, ejes de actuación y herramientas de soporte que de manera coordinada y planificada contribuyan a alcanzar las metas propuestas por las organizaciones (Villafañe, 1999; Xifra, 2005; Timoteo, 2013; Argenti, 2014; Puertas, Cadme y Alvarez, 2015; Madroñero y Capriotti, 2018).

Esta planificación estratégica adquiere especial relevancia en el escenario actual de constantes transformaciones tecnológicas, que están redefiniendo ya no sólo la manera de establecer relaciones con los públicos, sino el propio rol de las instituciones en la sociedad. Y es que el desarrollo de herramientas digitales ha puesto en cuestión el modelo clásico de emisiones privilegiadas y recepciones pasivas, dotando a la ciudadanía de un sistema de comunicación bidireccional, que la convierte en parte activa de los procesos de intercambio de mensajes (Almansa y Castillo, 2014; Van Ruler, 2015; Gershon, 2016). Para Quintana, Sosa y Castillo (2018: 253):

La visión conversacional o más bien dialógica de las relaciones públicas 2.0 requiere que las organizaciones se involucren en las conversaciones de forma activa y participativa a base de contenido tanto propio como aportado por sus fans o seguidores/ as. Esto significa que las organizaciones se ven necesitadas de involucrarse en las conversaciones a tiempo real con un gran abanico de públicos, generando un diálogo que implica la escucha activa de las opiniones de sus públicos.

En el caso concreto de los museos, el uso del espacio digital y de sus respectivas herramientas de comunicación ha conllevado a superar las funciones social y culturalmente establecidas para este tipo de organizaciones -adquisición, con- 
servación y exposición del patrimonio (Viñarás, 2005)- llegando incluso a un conocimiento exhaustivo de sus tipos de públicos. Para Martínez (2012: 394) la novedad radica en que ahora es la institución "quien debe buscar o localizar las conversaciones que sobre ella misma se puedan estar produciendo y tener una presencia activa en aquellas plataformas donde su público participa, intercambia opiniones o genera contenidos de interés para el museo".

Las redes sociales online se erigen hoy como los espacios por excelencia en los que transcurre esa comunicación en tiempo real, con capacidades de producción, distribución, alcance e influencia a nivel trasnacional. Se trata de "plataformas de gestión de bajo coste, con potencial viral y global y su fundamento común es hacer la comunicación fácil y accesible" (Quintana, Sosa y Castillo, 2018: 249).

Aunque estas características resultan comunes a la gestión de perfiles personales, organizacionales, empresariales, etc., De las Heras, Ruiz y Paniagua (2018: 94) advierten que en el caso de las redes sociales de instituciones hay que tener en cuenta además su vocación de servicio público "en el que debe predominar la comunicación eficaz y la escucha activa; la transparencia, ayudando a la institución a mostrarse tal y como es; la calidad del servicio y la corresponsabilidad".

El éxito del manejo de estas plataformas requiere de la actividad profesional que a menudo se ejecuta desde los departamentos y áreas destinadas a la comunicación institucional, para comunicar a los públicos la identidad y la marca de estos centros e intentar hacer de su oferta cultural también un atractivo turístico (Gershon, 2016; Chic, 2018). Ello es posible a través del uso de múltiples herramientas que, según las características específicas de cada red social, permiten satisfacer determinadas necesidades comunicativas de la comunidad digital de usuarios que, en este caso, se interesan por algún tipo de información sobre los museos.

De esta forma, se diluyen las barreras físicas que dividen a grandes y pequeños museos por cuestiones de localización o dimensión (Cano y Rostoll, 2018), y el reto se reduce a la gestión de una comunicación eficaz, a la usanza de las tendencias más avanzadas de la digitalización, para la obtención de beneficios y la consecución de objetivos según las necesidades organizacionales, los cambios motivacionales del público, la creciente competencia, y la flexibilidad y personalización a la que están sometidas las actividades turísticas (Beltrán, Parra y Padilla, 2017), sobre todo aquellas que se desarrollan en ámbitos menos globales, como es el caso de las que realizan los museos malagueños.

\subsection{Málaga, ciudad de museos}

Málaga ha sido objeto de interés turístico desde tiempos inmemoriales; sin embargo, el motivo de atracción ha variado a lo largo de los últimos años. Barrera y Meethan (2014) advierten que las primeras guías acerca de la ciudad estaban interesadas en las iglesias y monumentos, además de en el clima. No sería hasta 1928 cuando Málaga se asocia por primera vez a Pablo Picasso; vinculación que se perpetúa en el tiempo hasta ser pieza clave en las estrategias económicas, como así queda reflejado en los planes turísticos desde 2006, donde ya se advierte la necesidad de crear un museo dedicado a la figura del pintor.

A partir de entonces, Málaga ha experimentado una transformación turística y un fuerte crecimiento en un corto espacio de tiempo que la ha convertido en una auténtica ciudad de museos. Con un total de 40 , la mayoría de ellos concentrados 
en el centro histórico, es una de las ciudades con mayor densidad de museos en su casco antiguo (Área de Turismo Ayuntamiento de Málaga, 2016).

Esto se corrobora atendiendo al Índice de Carga Turística que, en términos de la Organización Mundial del Turismo, responde al número máximo de personas que pueden visitar un destino turístico al mismo tiempo, sin causar la destrucción del entorno físico, económico, sociocultural, ni una disminución de la calidad de la satisfacción de los visitantes.

Málaga lidera el ránking de dicho índice, con una media de 81,4 visitas museísticas por cada 100 pernoctaciones hoteleras registradas en la ciudad. Le sigue Valencia y Madrid con 55,5 y 51,0 visitas por cada 100 pernoctaciones hoteleras, respectivamente y, por último, Barcelona y Sevilla con 33,4 y 21,2 visitas por cada 100 pernoctaciones hoteleras. Asimismo, Málaga se sitúa en la cuarta posición en el ránking de las ciudades con alta oferta museística con 1,8 millones de visitas, superada por Madrid (9 millones), Barcelona (6,2 millones) y Valencia (1,9 millones), según datos del Estudio de la oferta y demanda de Museos en la Ciudad de Málaga (Área de Turismo Ayuntamiento de Málaga, 2016).

Respecto al impacto económico, los doce principales museos de Málaga fueron visitados por un total de 2.011.000 de personas, realizando un gasto medio por viaje de 612,5 euros. El impacto directo que genera el gasto de los visitantes con motivación museística, una vez descontada la parte de la demanda que se satisface con importaciones y a precios básicos, se cifra en 295,3 millones de euros. Esta nueva demanda se concentra en el sector del comercio, hostelería y transporte, así como en actividades inmobiliarias. A partir de aquí, se estima que ha generado unos 6.100 empleos (Área de Turismo Ayuntamiento de Málaga, 2016).

Cabe destacar que cinco de los diez primeros museos de España que aparecen en el ránking del Índice de Carga Turística son malagueños; en concreto el Centro de Arte Contemporáneo (CAC) está en segundo lugar; el Museo Picasso, en el tercer puesto; el Centre Pompidou en octavo; el Museo Carmen Thyssen en el noveno, y la Fundación Picasso-Casa Natal en el décimo.

El Centro de Arte Contemporáneo, de titularidad municipal y gestión privada, ha sido el primer centro y museo de arte en España que ha obtenido la certificación de calidad internacional. Situado en el antiguo Mercado de Mayoristas de Málaga, el edificio es de estilo racionalista y está declarado Bien de Interés Cultural. El CAC, que abrió sus puertas en 2003, tiene una clara vocación de museo internacional; sus exposiciones lo han situado como uno de los referentes del circuito europeo de este tipo de museos. De los 6.000 metros cuadrados de superficie total, 2.400 se destinan a exposiciones, aumentando la colección permanente ya sea a través de adquisiciones del Ayuntamiento de Málaga o por donaciones privadas.

La sede del Museo Picasso, en pleno centro histórico de la ciudad, se halla en el Palacio de Buenavista, ejemplo de la arquitectura andaluza del siglo XVI. Declarado Monumento Nacional en 1939 y después de haber sido sede del Museo de Bellas Artes de Málaga, abrió sus puertas en 2003 ya con la colección cedida por Paul, Christine y Bernard Ruiz-Picasso. Alberga una colección permanente que muestra ocho décadas del trabajo del pintor malagueño, con un total de 233 obras. La gestión del museo es llevada a cabo por una fundación de carácter privado en cuyo patronato participa la Junta de Andalucía. 
El Centre Pompidou, inaugurado en 2015, está situado en el puerto de Málaga, en un espacio conocido como "El Cubo" y es una sede del Centro Nacional de Arte y Cultura Georges Pompidou de Francia. Su colección permanente está formada por casi 90 obras que recorren el arte de los siglos XX y XXI, cedidas por el museo francés. Su gestión se realiza a través de la Agencia Pública para la Gestión de la Casa Natal de Pablo Ruiz Picasso y Otros Equipamientos Museísticos y Culturales. Inaugurado en 2011, el Museo Carmen Thyssen tiene su sede en un edificio renacentista palaciego del siglo XVI, situado en el centro histórico de la ciudad. Está gestionado por una fundación de carácter privado, siendo el edificio propiedad del Ayuntamiento de Málaga y la colección permanente de 285 obras de artes cedidas gratuitamente durante 15 años.

La Fundación Picasso, o Casa Natal Picasso, situado en pleno centro de la ciudad, está declarado Monumento Histórico-Artístico de Interés Nacional. La Fundación Picasso (Agencia Pública para la Gestión de la Casa Natal de Pablo Ruiz Picasso y Otros Equipamientos Museísticos y Culturales) es la encargada de planificar y gestionar los equipamientos museísticos de titularidad municipal, entre los que se encuentra la Casa Natal Picasso. Con una colección de obras de arte compuesta por más de cuatro mil piezas de más de 200 artistas, el museo ofrece un recorrido que vincula al pintor con su ciudad natal.

\section{Metodología}

Esta investigación centra su objeto de estudio en la gestión comunicativa del patrimonio cultural que realizan en redes sociales los museos malagueños. La selección de la muestra se justifica atendiendo a la posición que ocupan estos centros en el ránking del Índice de Carga Turística, que relaciona el número de pernoctaciones hoteleras y entradas a museos. Tal y como se ha especificado anteriormente, cinco de los diez primeros museos de España que aparecen en este ránking se encuentran en Málaga. Pertenecen a este listado el Centro de Arte Contemporáneo (CAC), que está en segundo lugar; el Museo Picasso, en el tercer puesto; el Centre Pompidou en octavo; el Museo Carmen Thyssen en el noveno, y la Fundación Picasso-Casa Natal en el décimo. Instituciones todas que constituyen un reclamo turístico competitivo, y que permiten que la capital de la Costa del Sol se posicione como una ciudad de museos.

Con el propósito de responder a los objetivos de la investigación se realizan entrevistas semiestructuradas a las responsables de comunicación y nuevos medios de los museos -Pepa Babot (Museo Picasso), María Navarro (Thyssen), Laura Rueda (Casa Natal y Pompidou) y Helena Juncosa (CAC)-, a partir de las cuales se conoce la forma en la que se estructuran dichos departamentos, el personal que gestiona la comunicación corporativa online, la presencia de estos museos en redes sociales, así como los beneficios que aporta dicha gestión a la funcionalidad turística del patrimonio que preservan estas instituciones.

Para determinar el impacto que tiene la gestión comunicativa de estos museos en redes sociales se acude al análisis de contenido de sus perfiles institucionales. Sólo se estudiaron aquellas redes en las que tienen presencia el universo de museos analizados (tabla 1), con el propósito de obtener resultados fiables al aplicar la misma herramienta de análisis a las redes que comparten estas organizaciones: Facebook, Twitter e Instagram. 
Tabla 1. Presencia de los museos en las redes sociales

\begin{tabular}{|c|c|c|c|c|c|c|c|c|c|c|}
\hline & $y$ & $f$ & $\begin{array}{l}\text { You } \\
\text { tubet }\end{array}$ & $f$ & fr & 8 & 우 & ๑ & $\theta$ & in \\
\hline CAC Málaga & $\checkmark$ & $\checkmark$ & $\checkmark$ & $\checkmark$ & $\checkmark$ & $\checkmark$ & $\checkmark$ & $\checkmark$ & $\checkmark$ & $\checkmark$ \\
\hline Museo Picasso Málaga & $\checkmark$ & $\checkmark$ & $\checkmark$ & $x$ & $x$ & $x$ & $\checkmark$ & $x$ & $x$ & $x$ \\
\hline $\begin{array}{c}\text { Centro Pompidou } \\
\text { Málaga }\end{array}$ & $\checkmark$ & $\checkmark$ & $\checkmark$ & $x$ & $x$ & $x$ & $\checkmark$ & $\checkmark$ & $x$ & $x$ \\
\hline $\begin{array}{l}\text { Museo Carmen } \\
\text { Thyssen Málaga }\end{array}$ & $\checkmark$ & $\checkmark$ & $\checkmark$ & $x$ & $x$ & $x$ & $\checkmark$ & $x$ & $x$ & $x$ \\
\hline Casa Natal de Picasso & $\checkmark$ & 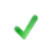 & $x$ & $x$ & $x$ & $x$ & 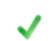 & $x$ & $x$ & $x$ \\
\hline
\end{tabular}

Fuente: Elaboración propia

El período de análisis comprende desde el 1 de diciembre de 2018 hasta el 1 de diciembre de 2019. El grado de interacción de los museos con sus públicos a través de las redes sociales se midió a partir de las estadísticas generadas por cada plataforma y de los informes que ofrece la herramienta de análisis web Fanpage Karma. Los indicadores de rendimiento estudiados responden al modelo PRGS, desarrollado por la IAB Social Media Council (Beltrán, Parra y Padilla, 2017) en función de (1) la Presencia en cada red social, que define la comunidad y la actividad del museo según el (a) número de seguidores y (b) esfuerzo comunicativo. (2) La Respuesta identifica las reacciones de los usuarios según los (c) Me gusta. Asimismo, (3) la Generación implica la creación de contenidos como son los (d) comentarios. Por último (4) la Sugerencia que recoge el número de (e) compartidos.

Recogida la información a través de las técnicas y herramientas ya declaradas y de la exhaustiva revisión bibliográfica documental, se procede a la triangulación de los datos y al reporte de los resultados de la investigación. 


\section{Resultados}

Todos los museos analizados cuentan con una estructura de comunicación, aunque en algunos casos sea unipersonal como el CAC, cuyo departamento se denomina Departamento de Comunicación y TICS. A pesar de no tener un presupuesto específico para redes sociales, desde este museo aseguran que "todo el impacto que tenemos es orgánico $100 \%$, este año vamos a invertir en torno a los 1.000 - 2.000 euros para incrementar la retroalimentación” (H. Juncosa, entrevista personal, 9 de enero de 2020).

En el Museo Picasso existe un Departamento de Comunicación y Prensa compuesto por la jefa del departamento y un puesto técnico, que se encargan de la "comunicación externa, la prensa, la web y las redes sociales" (P. Babot, entrevista personal, 9 de enero de 2020). A pesar de que no se ha facilitado a esta investigación el presupuesto total destinado a la comunicación, sí declaran que una parte de este se dedica a las redes sociales y se invierte en herramientas de gestión (Hootsuite), de audio (SoundCloud) o de tratamiento y creación de imágenes (PickMonkey).

El Museo Carmen Thyssen cuenta con un Departamento de Promoción y Comunicación que tiene un presupuesto anual de 397.397 euros. Además de la responsable del departamento, Lourdes Moreno, hay una persona exclusivamente dedicada a gestionar la web del museo, así como las redes sociales.

Por último, GAP Desing es la empresa encargada de la comunicación de la Casa Natal y del Pompidou. El Departamento de Comunicación, nombre que recibe, está compuesto por siete personas, siendo una de ellas la coordinadora de comunicación online y social media. En este caso la cuantía que se destina a comunicación "depende de los presupuestos anuales del Ayuntamiento de Málaga y de las campañas necesarias que haya que realizar para cada actividad” (L. Rueda, entrevista personal, 8 de enero de 2020).

\subsection{Impacto de la gestión de la comunicación de los museos en redes sociales}

La muestra objeto de estudio publica en Facebook para un total de 134.777 seguidores, lo que supone un promedio de 26.955,4 perfiles. El museo que más followers acumula es el CAC (37,3\%), seguido del Centre Pompidou (22,6\%) y el Museo Picasso (20,7\%). Diez puntos porcentuales diferencia a este último con la Casa Natal (10,4\%) y el Museo Carmen Thyssen (8,9\%), tal y como se puede observar en el gráfico 1. 
Gráfico 1. Número de seguidores en Facebook

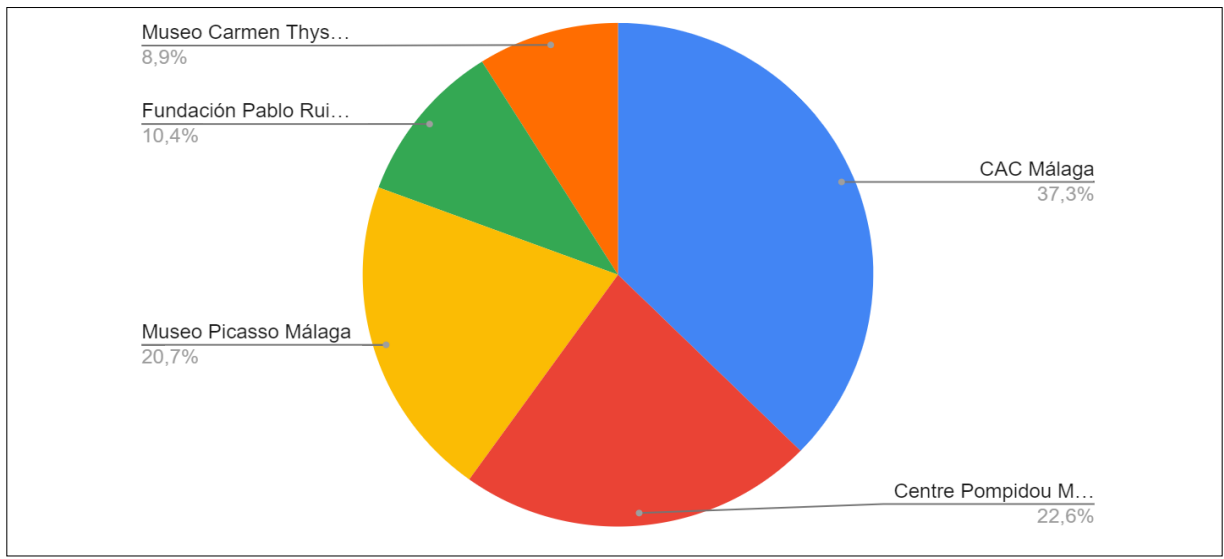

Fuente: Elaboración propia

Respecto al esfuerzo comunicativo (gráfico 2), a lo largo del año de estudio se publicaron en esta red social un total de 1.978 post. Un promedio de 396 actualizaciones. Del total, un 41,5\% corresponde al Museo Picasso y un 20,5\% al CAC. Le continúan el Carmen Thyssen (14,5\%), el Centre Pompidou (13,2\%) y la Casa Natal (10,4\%). En relación con el número de publicaciones por día, el Museo Picasso tiene de media 2,24 y el CAC, 1,10. A este respecto, el Carmen Thyssen y el Centro Pompidou publican 0,78 y 0,71 publicaciones de media al día, mientras que la Casa Natal 0,56.

\section{Gráfico 2. Esfuerzo comunicativo en Facebook}

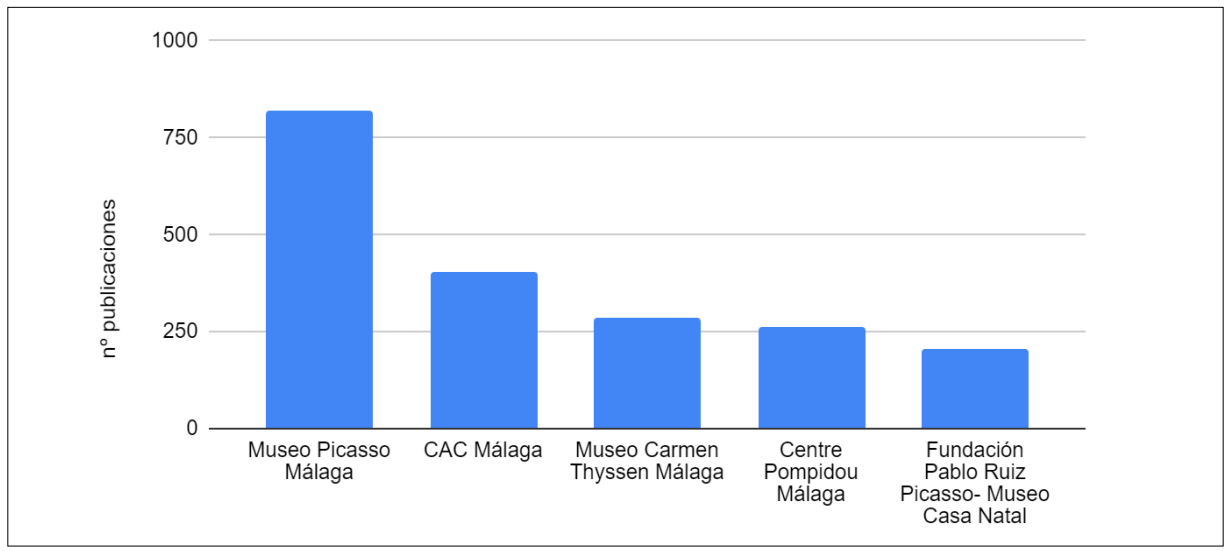

Fuente: Elaboración propia 
En el gráfico 3 se puede comprobar que las publicaciones antes mencionadas lograron 24.793 Me gusta ( $\mathrm{x}=4958,6)$. Concretamente, 8.502 Me gusta fueron para el Museo Picasso, es decir, un 34.3\% del total. El CAC logró 3.528 (22,5\%) mientras que el Centre Pompidou 3.528 (14,2\%). Del mismo modo, la cantidad de comentarios fue de 642 en total, un promedio de 128. El Museo Picasso logró el mayor número de comentarios, que corresponde a un 47,4\%. En segunda posición destaca el CAC $(20,7 \%)$ continuado por el Museo Carmen Thyssen (14,2\%). De entre todas, la actualización que granjeó mayor número de comentarios durante el período de análisis fue la realizada por el CAC a tenor del nombramiento de Fernando Francés como Secretario de Innovación Cultural y Museos de la Junta de Andalucía.

Gráfico 3. Reacciones en Facebook

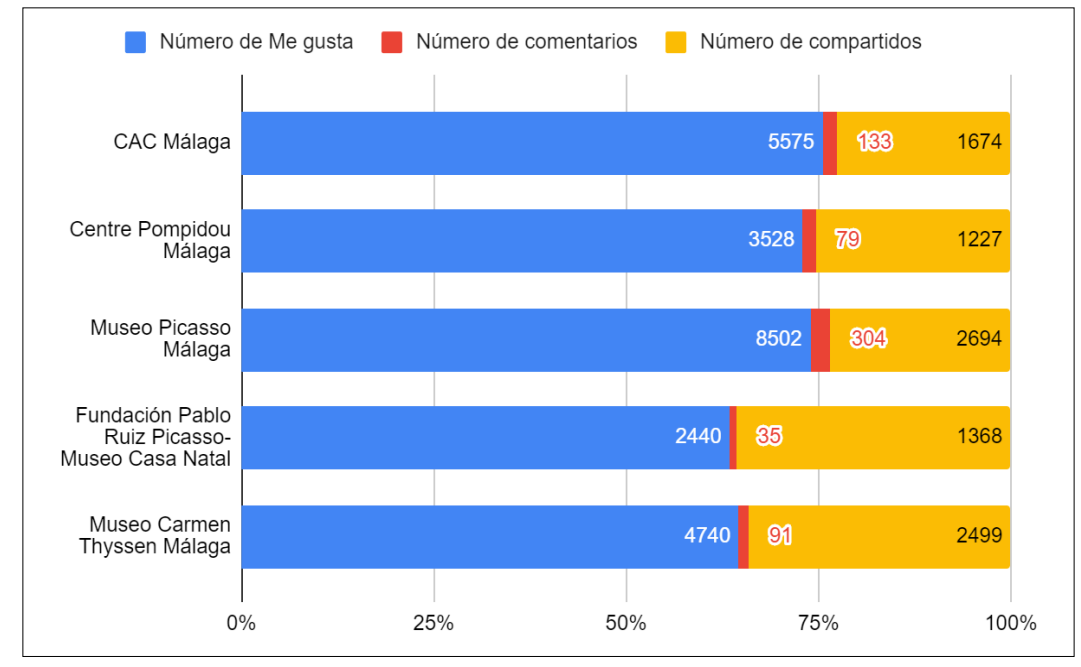

Fuente: Elaboración propia

Atendiendo a la cantidad de compartidos, 9.462 en total $(\mathrm{x}=1.892,4)$, el Museo Picasso fue aquí también la institución preponderante $(28,5 \%)$ seguida del Carmen Thyssen $(26,4 \%)$ y el CAC $(17,7 \%)$. Casa Natal $(14,5 \%)$ y el Centre Pompidou (13\%) cierran la lista. Al igual que con los comentarios, cabe destacar que el post que más se difundió entre la comunidad fue, como figura en la imagen 1, el publicado por Casa Natal a tenor del aniversario de la muerte de Picasso. 


\section{Imagen 1. Post más compartido en Facebook}

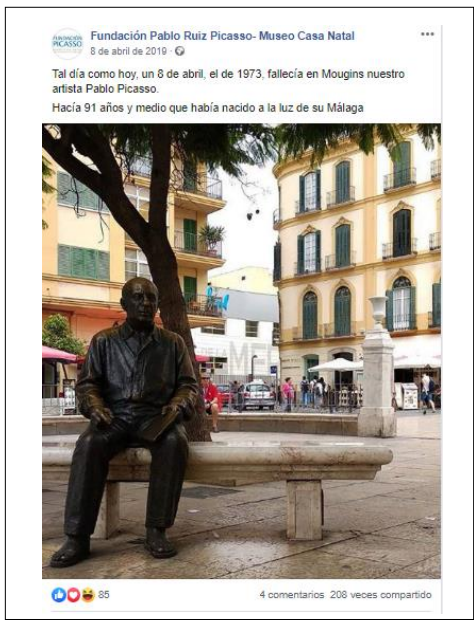

Fuente: Elaboración propia

En Twitter (gráfico 4) los museos malagueños comunican a un total de 28.2016 followers (x=56.403,2). El Museo Picasso es el que más seguidores aglutina (60\%), junto con el CAC (18,8\%) y el Carmen Thyssen (14,6\%). Le siguen Pompidou (3,9\%) y la Casa Natal $(2,7 \%)$.

\section{Gráfico 4. Número de seguidores en Twitter}

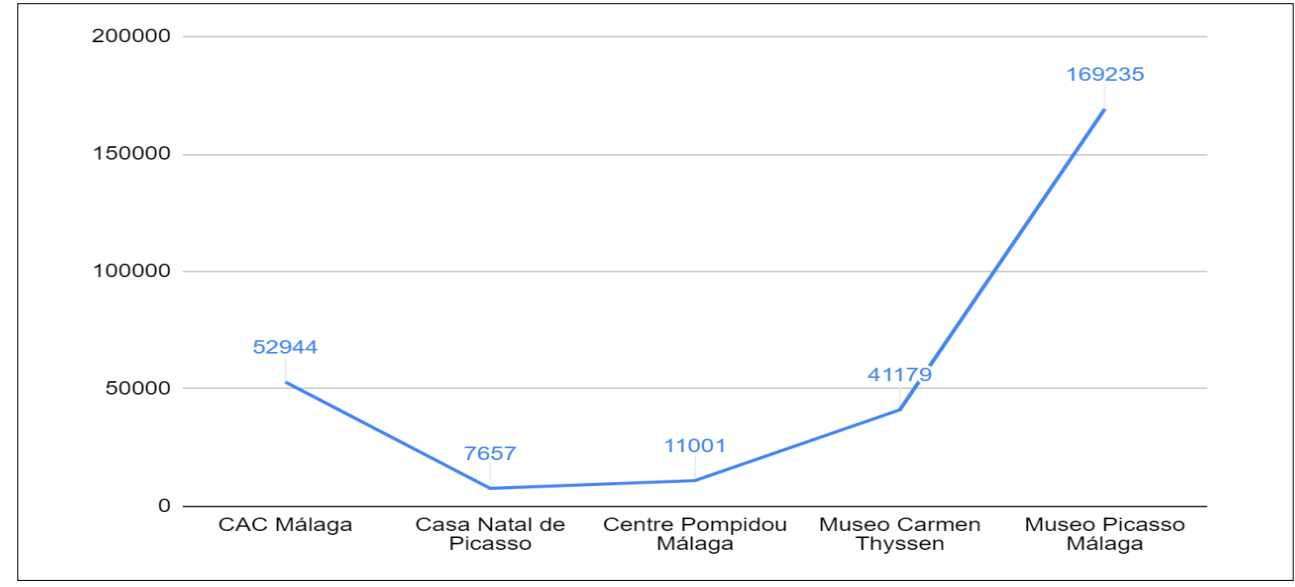

Fuente: Elaboración propia 
Se publicaron aquí 4.466 tuits, siendo el 34,1\% del Museo Picasso. El Centre Pompidou le continúa con un 22,9\% (gráfico 5), la Casa Natal (16,7\%), el Carmen Thyssen $(15,1 \%)$ y el CAC $(11,2 \%)$.

\section{Gráfico 5. Esfuerzo comunicativo en Twitter}

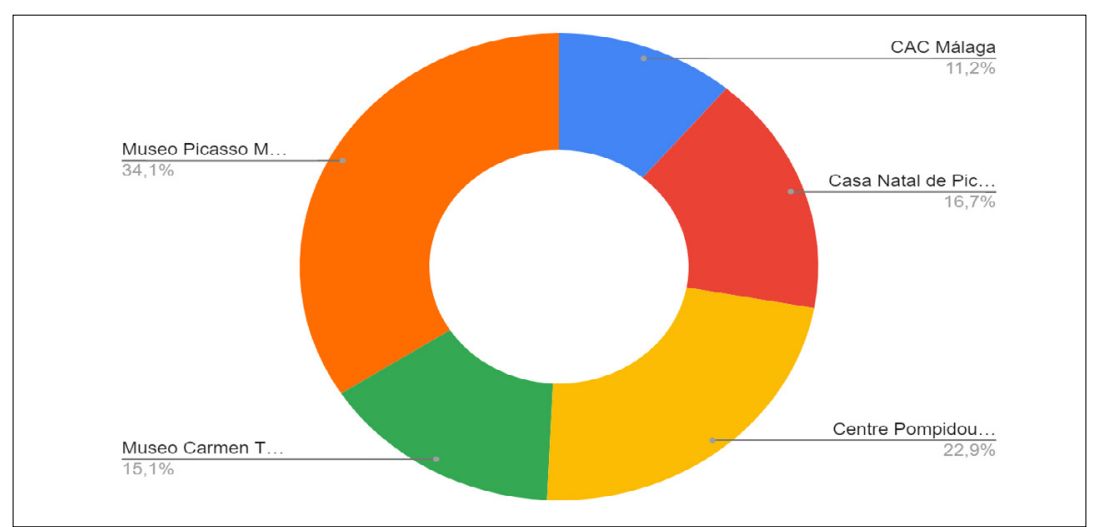

Fuente: Elaboración propia

El Museo Picasso es quien más tuitea al día con una media de 4,16; muy por delante del Centre Pompidou (2,79) y la Casa Natal $(2,03)$. Cierran esta lista el Carmen Thyssen y el CAC publicando al día 1,84 y 1,36, respectivamente. Asimismo, el número de Me gusta (gráfico 6) ascendió a 23.563 volviendo a ser el Museo Picasso quien más reacciones consagró (40,5\%), seguido del Carmen Thyssen (33,5\%) y el Pompidou (12,8\%). Por último, Casa Natal $(9,2 \%)$ y el CAC $(4,1 \%)$.

\section{Gráfico 6. Me gusta en Twitter}

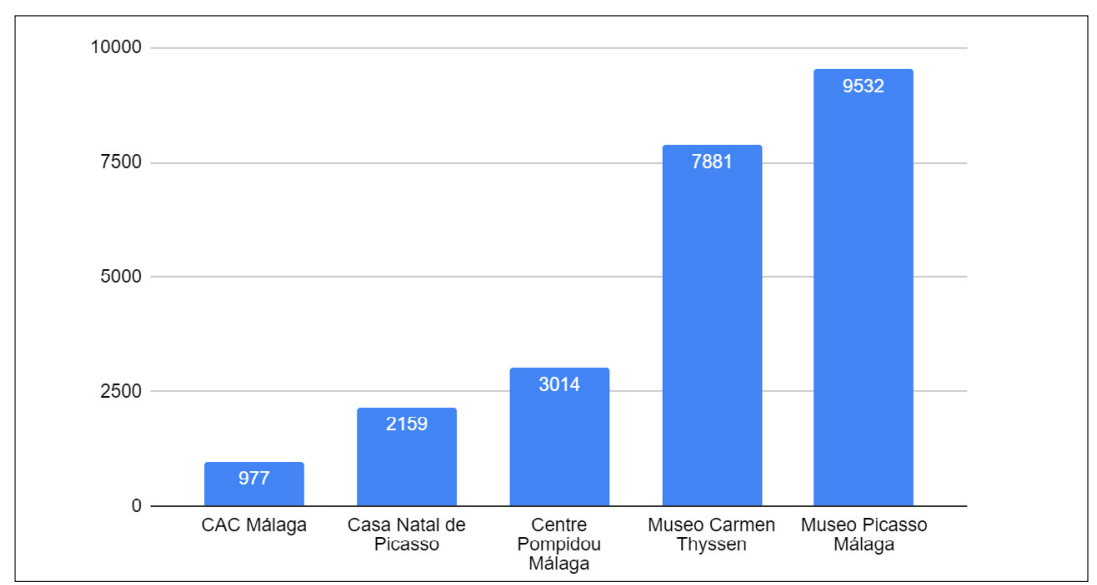

Fuente: Elaboración propia 
En lo que respecta al contenido compartido en esta red social, el 38\% lo alcanza el Museo Picasso junto con el Carmen Thyssen. El 11\% le corresponde al Pompidou y, por último, la Casa Natal y el CAC con un $8 \%$ y un 5\%, respectivamente. El tuit que más Me gusta (299) y Retuit (39) logró, tal y como aparece en la imagen 2, fue el publicado por el Museo Picasso y tuvo como objeto una de las actividades del museo durante el Festival de Málaga.

\section{Imagen 2. Publicación con más reacciones en Twitter}

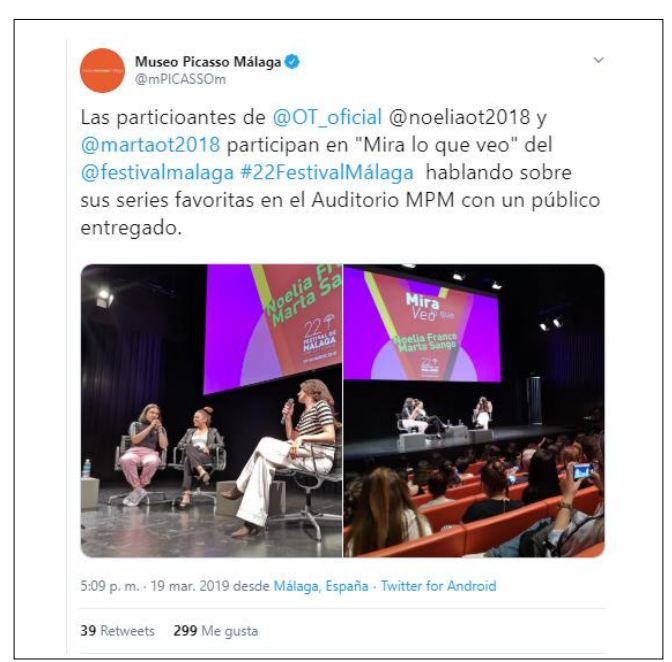

Fuente: Elaboración propia

En última instancia, en Instagram los museos actualizan para 122.491 seguidores (x=24.498,2). El Museo Picasso es el que más followers aglutina (46,3\%) junto con el CAC $(25,5 \%)$ y el Pompidou (19,9\%). Esto no corresponde con el esfuerzo comunicativo desarrollado. De total publicado, 879 post, y en base a este indicador, el Pompidou presenta el porcentaje más alto en número de publicaciones (32,5\%), seguido de la Casa Natal $(24,1 \%)$ y el Museo Picasso (21,2\%). Por su parte, la ratio de publicaciones por día revela que el museo Pompidou actualiza una media de 0,78 y la Casa Natal 0,57, amén del 0,50 del Museo Picasso. 
Gráfico 7. Reacciones en Instagram

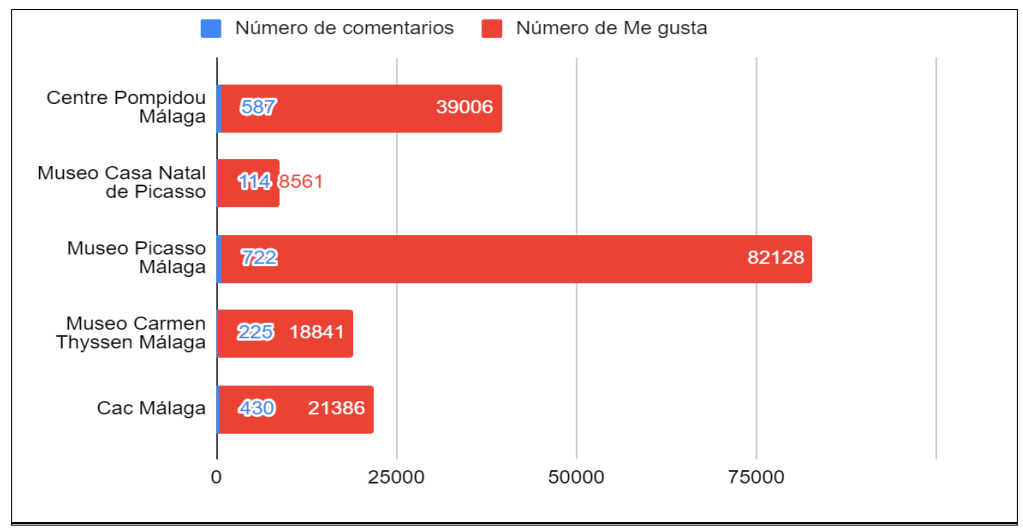

Fuente: Elaboración propia

Se detectó aquí un total de 169.922 Me gusta (gráfico 7), de los cuales, un 48,3\% responde al perfil del Museo Picasso (imagen 3), muy por delante del Pompidou (23,0\%) y el CAC (12,6\%). Las actualizaciones generaron 2.078 comentarios, 415,6 de promedio. Un $34,7 \%$ en la cuenta del Museo Picasso y un 28,2\% en la del Centre Pompidou.

Imagen 3. Post con más Me gusta en Instagram

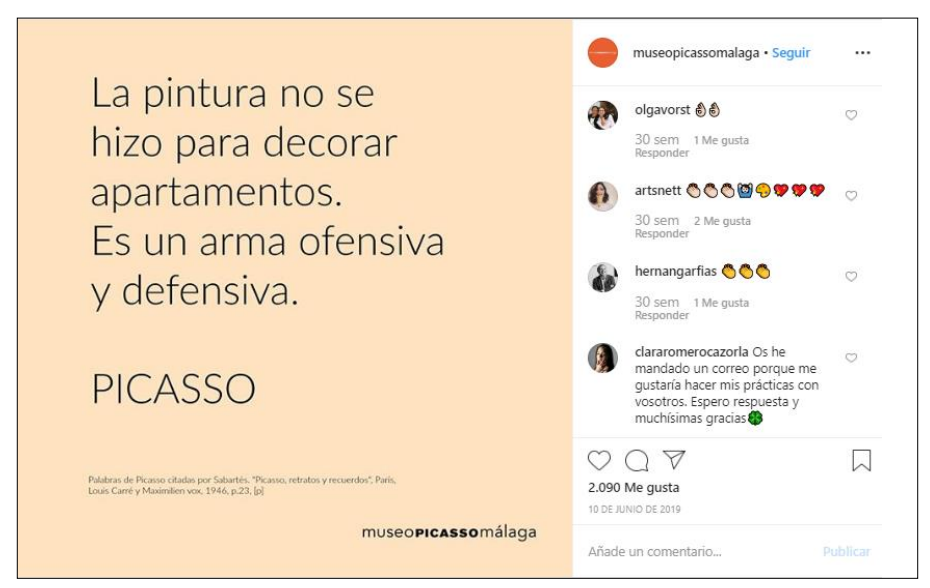

Fuente: Elaboración propia 


\subsection{Beneficios del impacto comunicativo de los museos en redes sociales}

Las potencialidades de Internet y las redes sociales para acercar al público, como nunca antes, la gestión del patrimonio cultural constituye uno de los beneficios de estas plataformas más reconocidos por las responsables de comunicación de los museos objeto de estudio. En efecto, "son una herramienta potentísima para conseguir la participación del público en nuestras actividades educativas (talleres, visitas, días de las familias...) y culturales (seminarios, conciertos, poesía, flamenco, jazz...)" (P. Babot, entrevista personal, 9 de enero de 2020).

La incorporación de los social media a la rutina de planificación de una experiencia cultural museística -que incluye desde la búsqueda de información sobre el centro, fotos, comentarios, precios, valoraciones de especialistas y público en general, posicionamiento en buscadores como actividad de ocio; hasta el momento de la visita y la difusión en redes de la experiencia y del conocimiento adquirido- ha aportado rendimientos concretos a estas organizaciones.

Desde el punto de vista cultural las entrevistadas reconocen que las redes sociales han fomentado nuevas formas de consumo del producto artístico, sobre todo a través de las visitas virtuales. Ello ha supuesto una transformación en la estrategia de comunicación de estas instituciones para crear productos digitales como galerías, audioguías, exposiciones, memorias, tiendas virtuales, críticas y reseñas adaptadas a las necesidades que exigen los usuarios online.

Para nosotros es tan importante la cantidad de usuarios que nos visitan como la calidad de la experiencia cultural que viven en el museo. De ahí que nuestra estrategia en redes sociales se enfoque no sólo a la atracción del público hacia nuestra oferta sino a fomentar el gusto por el arte desde determinados valores éticos y estéticos. Por supuesto, deseamos que si vienen a Málaga nos visiten, pero esencialmente que conozcan sobre la vida y obra de Pablo Picasso, nuestra colección y nuestras exposiciones (P. Babot, entrevista personal, 9 de enero de 2020).

Otro de los beneficios para el sector museístico del impacto generado por las redes radica en la democratización de la cultura, teniendo en cuenta su transversalidad a la vida cotidiana, que se desarrolla también en el espacio virtual. Las entrevistadas aluden a la capacidad institucional de estos centros para compartir el patrimonio que preservan más allá de su mera exposición, a través de la realización de múltiples actividades que son difundidas y consumidas en las redes sociales, y segmentadas según los tipos de públicos.

Aunque algunos museos otorgan el mismo valor a las redes analizadas, potenciándolas por igual, otros sí reconocen el beneficio que aporta la especialización. En el Museo Picasso:

La red social que más se potencia es Instagram puesto que nos ayuda a visualizar y fomentar la retroalimentación con nuestros usuarios. Además, nos permite ofrecer información en primicia, transmitir en directo mediante los stories de la app y crear un contenido más creativo y dinámico (P. Babot, entrevista personal, 9 de enero de 2020).

En el caso del Museo Thyssen se potencia Twitter "ya que es la red social con más interacción y mayor número de seguidores. Actualmente también se pone el foco en Instagram para tratar de llegar al público más joven" (M. Navarro, entrevista personal, 8 de enero de 2020).

Estos resultados en términos culturales tienen un impacto en la funcionalidad turística que genera la gestión de la comunicación de los museos en el espacio digital. Ello permite posicionar a Málaga como destino turístico cultural, lo cual se 
traduce en efectos económicos concretos del turismo de museos para la ciudad y repercute en un aumento del número de visitantes que reciben.

Al cierre de 2019 el Picasso registró un total de 703.807 visitas, lo que supone un incremento del 4\% respecto al año 2018. "Del total de visitantes el 70\% proviene del extranjero, a pesar de que no creamos regularmente contenidos en otros idiomas. Lo hacemos sólo de forma ocasional en Instagram, Twitter, Facebook y en algunos seminarios internacionales” (P. Babot, entrevista personal, 9 de enero de 2020).

Helena Juncosa declara que de los 475.044 visitantes que acudieron al CAC en 2018, el 23,40\% lo hizo motivado por la comunicación de la institución en redes sociales (entrevista personal, 9 de enero de 2020). Cifra similar registra el Museo Thyssen en 2019, con un 28\% de sus usuarios que reconocen haber visitado el museo a propósito de su gestión comunicativa en redes sociales.

Para nosotros el trabajo de comunicación en las redes ha supuesto un incremento del número de visitas. Además, nos sirven como canal de atención al visitante, quienes nos hacen consultas sobre su visita al museo. De ahí que la institución ha puesto en marcha un plan de marketing digital y está invirtiendo presupuesto en campañas en Google Ads y redes sociales (M. Navarro, entrevista personal, 8 de enero de 2020).

Desde el Centre Pompidou y la Casa Natal aseguran haber recibido un feedback positivo de los usuarios que han acudido al museo gracias a las publicaciones de esta institución en redes sociales:

En ocasiones los visitantes han declarado que a pesar de tener en su ciudad estos centros de arte desconocen lo que pueden encontrar en su interior, y que nuestras publicaciones en las redes le han acercado el contenido, suscitando su curiosidad y finalmente su visita (L. Rueda, entrevista personal, 8 de enero de 2020).

Existe el criterio compartido entre las responsables de comunicación de los museos analizados, de que el atractivo turístico que generan estos centros para los usuarios de las redes sociales no es resultado únicamente de la gestión institucional, sino también del contenido generado por los propios usuarios de la web, quienes contribuyen a una mayor visibilidad de estos espacios culturales y a su reconocimiento como actividad de ocio y vacaciones.

\section{Discusión y conclusiones}

Las redes sociales han supuesto, tal y como postuló Viñarás (2005), una superación de las funciones preestablecidas para instituciones como los museos, y el uso del espacio digital favorece un conocimiento de los públicos. Así se ha ratificado tras el análisis de la comunicación de los museos de la ciudad de Málaga que este estudio realiza; sin embargo, en estos casos, las redes sociales se implementan desde un estadio aún primario, por lo que todavía no han alcanzado el nivel de especialización y optimización necesario en la transmisión de los mensajes a sus públicos.

A tenor de lo expuesto por Quintana, Sosa y Castillo (2018) cuando enuncian el bajo coste que supone para la generalidad de los usuarios la comunicación en redes sociales, esta investigación ha constatado que en el caso de instituciones como los museos es necesario contar además con un departamento de comunicación que responda a una estructura sólida, 
dotada de personal especializado y presupuesto suficiente para ejecutar su labor; algo de lo que adolecen algunos de los centros analizados.

No obstante, llama la atención que siendo el museo Casa Natal de Picasso la institución cultural que cuenta con una plantilla mayor en su departamento de comunicación, esta fortaleza no se traduzca en la obtención de los mejores datos y posicionamiento en la gestión de las redes sociales, en comparación con el resto de los museos analizados. Y es que como aseguran De las Heras, Ruiz y Paniagua (2018), una gestión comunicativa eficaz se evidencia tanto en la calidad del servicio como en la rentabilidad de los esfuerzos para conseguirla.

De los resultados se infiere que los museos muestran un interés manifiesto por comunicar a través de redes sociales; sin embargo, este esfuerzo por transmitir mensajes no es correspondido por parte de los públicos de manera proporcional en todas las redes. De hecho, a pesar de que las instituciones estudiadas comunican más asiduamente en Twitter, la comunidad de seguidores más numerosa y que tiene una mayor interacción entre institución y públicos es Facebook.

En términos generales, la capacidad para publicar es alícuota a la cantidad de reacciones logradas. Por tanto, los museos que más asiduamente actualizan sus redes sociales resultan los que más Me gusta y comentarios reciben. De este modo, el Museo Picasso es el que realiza el mayor esfuerzo comunicativo y el que más reacciones genera en todas las redes sociales, excepto en Instagram, sobre la que declaran tiene limitaciones para su línea editorial. No obstante, resulta llamativo que, sin realizar grandes esfuerzos comunicativos en esta red, el Picasso sea el museo que más feedback recibe de su comunidad virtual, por encima del Centre Pompidou y el CAC que sí potencian el trabajo en Instagram.

Por otra parte, a pesar de que desde las instituciones afirman mantener un diálogo abierto con los usuarios a través de mensajes privados, el estudio advierte una carencia significativa en el volumen de comentarios generados por cada publicación; lo que denota una ausencia de conversación entre las organizaciones y sus públicos en cualquiera de las tres redes estudiadas. Algo que podría mejorar implementando actualizaciones que lo fomenten. Instagram descolla como el social media con mejor rendimiento al detectarse un elevado número de comentarios generados a partir del menor número de publicaciones.

Respecto al contenido, cabe destacar que, aunque se advierte un esfuerzo realizado por las instituciones a la hora de actualizar promocionando sus actividades, los post que más reacciones generan no son aquellos llamados a atraer visitantes al museo, sino aquellos relacionados con la figura del artista, como es el caso del museo Picasso, o con temas sobre arte y cultura.

Del impacto de la gestión de la comunicación corporativa en redes sociales al que aluden Martínez (2012) y De las Heras, Ruiz y Paniagua (2018) se aprecia, por un lado, su notable influencia en la transformación de las formas de planificación y consumo del producto cultural. En los casos objeto de estudio dicha gestión aparece más enfocada a la calidad de la experiencia museística que a su cantidad, aun cuando esto constituye un indicador muy relevante en la estrategia comunicativa de los museos.

Por otro lado, se evidencia una aportación de estos centros a la democratización de la cultura, en tanto la gestión comunicativa del patrimonio que atesoran persigue la participación de los públicos y supera los estándares expositivos tradicionalmente asociados a la actividad museística. 
Se concluye que los beneficios de la gestión comunicativa reafirman la funcionalidad turística de los museos analizados, demostrada tanto en el porcentaje de usuarios que llegan a ellos través de las redes, como en el aumento anual de visitantes en términos absolutos.

\section{Referencias bibliográficas}

Almansa, A. y Castillo, A. (2014). Comunicación Institucional en España. Estudio del uso que los diputados españoles hacen de las TIC en sus relaciones con la ciudadanía. Chasqui Revista Latinoamericana de Comunicación, 126, 22-30. https://doi.org/10.16921/chasqui.v0i126.250

Área de Turismo Ayuntamiento de Málaga. (2016). Estudio de la oferta y demanda de Museos en la Ciudad de Málaga. Recuperado de http://www.malagaturismo.com/es/paginas/informes/362

Argenti, P. (2014). Comunicación estratégica y su contribución a la reputación. Madrid: LID editorial.

Barrera, D. \& Meethan, K. (2014). The Relationship of City Branding and Tourist Promotion: The Case of Plymouth (UK) and Malaga (Spain). Athens Journal of Tourism, 1(3), 217-226. https://doi.org/10.30958/ajt.1-3-4

Becerra, E. y Domínguez, B. (2014). Museos, comunicación y jóvenes: la comunicación y sus efectos en la población de referencia del museo. Historia y Comunicación Social, 19, 603-611. http://dx.doi.org/10.5209/rev_HICS.2014.v19.44988

Beltrán, M.A, Parra, M. C. y Padilla, J. M. (2017). Las redes sociales aplicadas al sector hotelero. International Journal ofScientific Management and Tourism, 3(2), 131-153. Recuperado de https://dialnet.unirioja.es/servlet/articulo?codigo=6132930

Caerols, R., Viñarás, M. y Gonzálvez, J. E. (2017). Redes sociales y museos: análisis de la campaña en Twitter para el Día Internacional de los Museos y Noche de los Museos. Revista Latina de Comunicación Social, 72, 220- 234.http://dx.doi. org/10.4185/RLCS-2017-1162

Cano, R. y Rostoll, J. (2018). Uso de las redes sociales en museos internacionales. RAE-IC: Revista de la Asociación Española de Investigación de la Comunicación, 5(9), 41-49. http://dx.doi.org/10.24137/raeic5.9.6

Chic, L. (2018). Los principales retos de las instituciones culturales con la comunicación online en la revolución 2.0. Culturas. Revista de Gestión Cultural, 5(2), 20-28. https://doi.org/10.4995/cs.2018.10579

Claes, F. y Deltell, L. (2019). Museo social en España: redes sociales y webs de los museos estatales. El Profesional de la Información, 28(3), 1-13 https://doi.org/10.3145/epi.2019.may.04

Cordón, D. y González, D. (2016). Museos y comunicación: los nuevos medios como herramienta de diálogo y sociabilidad de la institución. El uso de Twitter por el museo del Prado, museo Thyssen-Bornemisza y museo Reina Sofía. Fonseca, Journal of Communication, 12(12), 149-165. https://doi.org/10.14201/fjc201612149165

De las Heras, C., Ruiz, I. y Paniagua, F. J. (2018). Gestión de la comunicación en las instituciones. Madrid: Pearson.

Falk, J. (2012). Identity and the museum visitor experience. London: Routledge.

Gershon, R. (2016). Digital Media and Innovation. Management and Design. Strategies in Communication. London: Sage. 
Gürel, E \& Kavak, B. (2010). A conceptual model for public relations in museums. European Journal of Marketing, 44(1-2), 42-65. http://dx.doi.org/10.1108/03090561011008600

Hood, M. (1983). Staying away. Why people choose not to visit museums. Museum News, 61(4), 50-57. Recuperado de https://ucl.rl.talis.com/items/5C19D575-312A-44F1-14CB-D98AA0E28246.html

Instituto de Turismo de España. (2018). Memoria de gestión 2018. Recuperado de https://www.tourspain.es/es-es/ con\%C3\%B3zcanos/memoria-anual

Jiménez, L. J. (2016). Museo y comunicación 2.0. Situación en España. Documentación de las Ciencias de la Información, 39, 177-203. http://dx.doi.org/10.5209/DCIN.54416

Legget, J. (2009). Measuring what we teasure or teasuring what we measure? Investigating where community stakeholders locate the value in their museums. Museum Management and Curatorship, 24(3), 213-232. http://dx.doi. org/10.1080/09647770903073052

Lazzeretti, L., Sartori, A., \& Innocenti, N. (2015). Museums and social media: the case of the Museum of Natural History of Florence. International Review on Public and Nonprofit Marketing, 12(3), 267-283. http://dx.doi.org/10.1007/ s12208-015-0136-5

Losada, J. C. y Capriotti, P. (2015). La comunicación de los museos de arte en Facebook. Comparación entre las principales instituciones internacionales y españolas. Palabra Clave, 18(3), 889-904. http://dx.doi.org/10.5294/pacla.2015.18.3.11

Madroñero, G. y Capriotti, P. (2018). La etapa de la Estrategia de Comunicación en el proceso de planificación de la comunicación y las relaciones públicas. Revista Internacional de Relaciones Públicas, 8(16), 171-186. http://dx.doi.org/10.5783/ RIRP-16-2018-10-171-186

Martínez, R. (2012). Estrategia comunicativa digital en el museo. El Profesional de la Información, 21(4), 391-395. http:// dx.doi.org/10.3145/epi.2012.jul.10

Mas, J. M. (2018). Museos españoles en Facebook: análisis de su comunicación como museos sociales. Revista de Comunicación, 17(2), 185-207. https://doi.org/10.26441/RC17.2-2018-A8

Mateo, S. (2019). El uso del museo como agencia de relaciones públicas de las empresas patrocinadoras: el papel de los medios de comunicación. Communication \& Society, 32(3), http://dx.doi.org/10.15581/003.32.3.51-66

Menor, J. A. (2019). Turismo colaborativo en la ciudad de Córdoba: análisis del perfil sociodemográfico, la motivación y la satisfacción de esta tipología de visitantes (tesis doctoral). Recuperada de https://helvia.uco.es/xmlui/handle/10396/18747

Merín, C. (2018). Estrategias digitales en museos: 41 ejemplos y buenas prácticas. En Ende comunicación. Recuperado de http://endecomunicacion.com/estrategias-digitales-en-museos-41-ejemplos/

Ministerio de Cultura y Deporte. (2019). Anuario de Estadísticas Culturales 2019. Recuperado de https:/ /www.culturaydeporte.gob.es/servicios-al-ciudadano/estadisticas/cultura/mc/naec/portada.html

Ministerio de Industria, Comercio y Turismo. (2019). Directrices de la Estrategia de Turismo Sostenible de España 2030. Recuperado de https://turismo.gob.es/es-es/estrategia-turismo-sostenible/Paginas/Index.aspx 
Oksuz, B. \& Gorpe, S. (2019). Public Relations or Corporate Communication? Concept Discussions of Academics and Professionals. Türkiye letiim Aratırmaları Dergisi, 33, 1-23. http://dx.doi.org/10.17829/turcom.514362

Oliveira, A. y Capriotti, P. (2013). Gestión estratégica de los públicos en museos. De la identificación a la comunicación. El Profesional de la Información, 22(3), 210-214. http://dx.doi.org/10.3145/epi.2013.may.03

Panozzo, A. (2018). La recepción en los museos. Exploraciones de los estudios de visitantes en los museos argentinos. Chasqui. Revista Latinoamericana de Comunicación, 139, 311-326. https://doi.org/10.16921/chasqui.v0i139.3385

Parguiña, S. (2015). Las motivaciones de los turistas que visitan los museos de A Coruña (trabajo fin de máster). Recuperado de https://ruc.udc.es/dspace/handle/2183/15553

Puertas, R., Cadme, E. y Alvarez, A. (2015). Gestión estratégica de la comunicación digital en la empresa ecuatoriana. Perspectiva comparada con la realidad europea. Revista Internacional de Relaciones Públicas, 5(9), 5-26. http://dx.doi. org/10.5783/RIRP-9-2015-02-05-26

Quintana, A. L., Sosa, A. y Castillo, A. (2018). Acciones y estrategias de comunicación en plataformas digitales. El caso Cifuentes. Prisma Social, 22, 247-270. Recuperado de https://revistaprismasocial.es/article/view/2585

Salmon, C., Poorisat, T. \& Kim, S. (2019). Third-person effect in the context of public relations and corporate communication. Public Relations Review, 45, 1-12. https://doi.org/10.1016/j.pubrev.2019.101823

Santos, E. (2012). Museos y comunicación: algunas reflexiones y consideraciones generales. En M. Asensio, et al. (Ed.), SIAM. Series Iberoamericanas de Museología (pp.79-85). Madrid: Universidad Autónoma de Madrid.

Soler, A. (2017). La gestión de la comunicación externa en los museos andaluces (tesis doctoral). Recuperado de https:// riuma.uma.es/xmlui/handle/10630/14315

Subdirección General de Museos Estatales. (2012). Conociendo a todos los públicos. ¿Qué imágenes se asocian a los museos? Recuperado de https://sede.educacion.gob.es/publiventa/d/14315C/19/0

Timoteo, J. (2013). El manejo de la comunicación organizacional: Espacios, herramientas y tendencias en gestión de negocios. Madrid: Ediciones Díaz de Santos.

Van Riel, C. (2005). Comunicación corporativa. Madrid: Prentice Hall.

Van Ruler, B. (2015). Agile Public Relations Planning: The Reflective Communication Scrum. Public Relations Review, 41(2), 187-194. https://doi.org/10.1016/j.pubrev.2014.11.008

Velasco, M. (2009). Gestión turística del patrimonio cultural: enfoques para un desarrollo sostenible del turismo cultural. Cuadernos de Turismo, 23, 237-254. Recuperado de https://revistas.um.es/turismo/article/view/70121

Villafañe, J. (1999). La gestión profesional de la imagen corporativa. Madrid. Ediciones Pirámide.

Viñarás, M. (2005). Una aproximación a la gestión de la comunicación en los museos: cambios y tendencias en el cambio de siglo. Revista de Comunicación Vivat Academia, 67, 38-64. http://dx.doi.org/10.15178/va.2005.67.38-64 
Viñarás, M. (2009). Departamentos de comunicación en museos: la planificación estratégica de la comunicación en instituciones artísticas y culturales. Global Media Journal, 6(11), 36-54. Recuperado de https://www.redalyc.org/articulo. oa?id=687/68711445003

Viñarás, M. (2011). La Gestión de la Comunicación en los Museos de Madrid: Auditoría de Relaciones Públicas. Madrid: CERSA.

Viñarás, M., Cabezuelo, F. y Herranz, J. M. (2011). La comunicación corporativa de los museos en España a través de la comunicación 3.0: cuatro años de evolución comunicativa en la Red. En F. Ortega y L. Cardeñosa (coord). Nuevos Medios, Nueva Comunicación. Libro de Actas del II Congreso Internacional Comunicación 3.0. Salamanca, 4-5 de octubre de 2010, 561-578. Salamanca: Universidad de Salamanca.

Xifra, J. (2005). Planificación estratégica de relaciones públicas. Barcelona: Paidós Ibérica. 